\title{
Restoration of Soil and Environment Through Modern Tools of Biotechnology
}

\section{Jyoti Prakash Sahoo ${ }^{1 *}$, Ambika Prasad Mishra ${ }^{2}$ and Kailash Chandra} Samal $^{2}$

${ }^{1}$ Department of Agricultural Biotechnology, Odisha University of Agriculture and Technology, India

${ }^{2}$ Department of Soil Science and Agricultural Chemistry, Odisha University of Agriculture and Technology, India

*Corresponding Author: Jyoti Prakash Sahoo, Department of Agricultural Biotechnology, Odisha University of Agriculture and Technology, India.

Microorganisms have been extensively evaluated in several biological based products made available to farmers for applications in agricultural development. These conventional developments in biotechnology, primarily designed to increase agricultural productivity and reducing synthetic chemical inputs, have gained interest as techniques for enhancing and preserving the status of soil health. In contrast to the concept of modern biotechnology, which involves deliberate manipulation of genes from different species to produce transgenic organisms using recombinant DNA or direct nucleic acid injection. In this context, plant phenotype characteristics have historically been selected, whereas significant beneficial interactions between plants and microbes that influence soil health have been ignored during selection of elite crop variety. The concept of soil biotechnology was described as the manipulation of soil microorganisms and the analysis of their metabolic processes to maximize the productivity of crop by Lynch in the year 1983. In the later $20^{\text {th }}$ century, the concept of modern biotechnology emerged with the technical advancement of plant molecular biology which allowed intentional manipulation of genes of different organisms to incorporate changes in the genetic makeup of a target organism by employing recombinant DNA or direct injection of nucleic acid into cells, resulting in genetically modified or transgenic organisms. Both definitions of biotechnology connect biological management to soil health and address the possibility of impact on soil health by implicitly manipulating microbial communities and act impulsively to genetically modified plants or microorganisms incorporated into crop, pastureland, and natural forest ecosystems.
Received: January 23, 2021

Published: February 27, 2021

(C) All rights are reserved by Jyoti Prakash

Sahoo., et al.
Soil health status tends to be an evolving concept, and a complete set of functional bio-indicators remains elusive, given the different accepted indicators of physical and chemical properties used for the assessment of soil health. Whereas substantial development of molecular soil microbiology enables the in-depth detection of biodiversity via soil microbial communities. The foundation for soil function, soil microbial diversity and microbial functional groups are not used in assessment methods as standard soil health indicators due to the lack of sufficient repositories and difficulty in designing in-field sampling techniques that maintain soil health. The complexity of the microbial communities and its roles further complicates the development of a functional set of biological indicators to provide surveillance to soil health. The Soil Management Assessment System (SMAF), which uses complex properties of soil or indicators that affect the soil function, is among the comprehensive frameworks for evaluating the effects of land management on soil resources. To generate a soil quality index or soil health index and to calculate soil's ability to work, a collection of indicators representing physical, chemical, and biochemical parameters are used. Using methods and services based on traditional biotechnology, crop and soil management emphasizes the role of soil biological processes but eventually integrates with physical and chemical properties to sync up soil functional capacity to maintain production of plants and reduce environmental disruption. The term 'soil biological fertility' has also been proposed to provide further insight on how specific biological properties respond to management practices, such as those based on biotechnology applications, in 
order to emphasize the importance of soil biological processes for optimal and sustainable soil health.

Modern biotechnology has led to numerous crop varieties with enhanced resistance to disease and insect pests, tolerance to drought and salinity, and herbicide resistance for simplified weed management in the field condition. These initiatives, nevertheless, have traditionally focused on the selection of crop phenotype characteristics, while during the varieties selection, substantial positive plant-microbe associations that influence soil health have been ignored. Therefore, the impact on soil health of products of modern biotechnology, mainly transgenic crops, contrasts dramatically with the agricultural biological products of traditional biotechnology. The structure, function, and diversity of the soil and rhizobial microbial communities may be indirectly affected by genetically modified crops. Microbes of the rhizosphere play a critical role in the soil-root environment, providing essential ecosystem services such as crop residue decomposition, resolving biogeochemical cycles within the soil food web, and maintaining ecological efficiency and performance. Transgenic crops, mainly corn (Zea mays L.) and cotton (Gossypium hirsutum L.), are designed to incorporate the Bacillus thuringiensis (Bt) bacterium gene Cry1Ab, that codes for the development of an insecticidal protein that kills Lepidopteran pests but it is also released through root exudation into soil system. Glyphosate-resistant crop cultivars were developed by introducing a transgene (cp4) from a species of Agrobacterium that codes for an insensitive form of 5-enolpyruvyl-shikimate-3-phosphatase synthase, a critical enzyme for the production of glyphosate-sensitive aromatic amino acids. Herbicide-resistant crops affect microbes of the rhizosphere as glyphosate introduced to crops is released into the environment of the rhizosphere through roots.

In addition, intact genetically modified DNA is released by root exudation and can be obtained by microbial communities by natural transformation, resulting in inter-cellular retention and replication within the microbial horizontal gene transfer network of foreign DNA sequences and may have unexpected environmental effects. The literature is replete with reports of the adverse effects of transgenic crop management on fundamental soil health indicators, despite a range of reviews indicating that transgenic crop systems have little or no significant effect on soil and environmental biological processes. In order to compare soil health with more sustainable cropping systems, modern biotechnology involving the use of genetically modified cropping systems has not been directly examined. Due to the critical roles, some groups of microorganisms perform relative to soil structure, soil organic matter formation, and nutrient cycling, the consistent negative impact of continuous planting of Bt and glyphosate-resistant crop varieties on soil fungi and mycorrhizae is especially alarming. In order to enhance soil health under the genetically modified cropping system, the application of techniques identical to that for enhancing plant biological processes by manipulating microbial consortia in the rhizosphere of genetically modified crops either to destroy Cry proteins and glyphosate or to boost pathways inside the root environment to resolve adverse conditions associated with the production of genetically modified crops may help.

Traditional biotechnology-developed agricultural biological products could be critical assets for both the improvement and conservation of soil health. Most are generally targeted at improving the plant growth and preserving plants from phytopathogens. Since most products have not been rigorously assessed, it is assumed that beneficial attributes of plant production are converted into soil health due to higher root biomass promoting higher microbial biomass and organic matter production which are the two keys for optimal soil health. With the existing availability of modern microbiological and rhizospheric diagnostic techniques for both the structure and function of plant-associated microorganisms, the biological composition and specific mechanism of action of biological products could be significantly improved in future. As the use of biological products becomes more widely accepted as a management component, it is expected that their effect on soil health could be described using a strategy for assessing soil health, similar to those already in effect which can quantify the effects of single practices, such as the use of manure as a modification of soil.

\section{Assets from publication with us}

- Prompt Acknowledgement after receiving the article

- Thorough Double blinded peer review

- Rapid Publication

- Issue of Publication Certificate

- High visibility of your Published work

Website: www.actascientific.com/

Submit Article: www.actascientific.com/submission.php

Email us: editor@actascientific.com

Contact us: +919182824667 